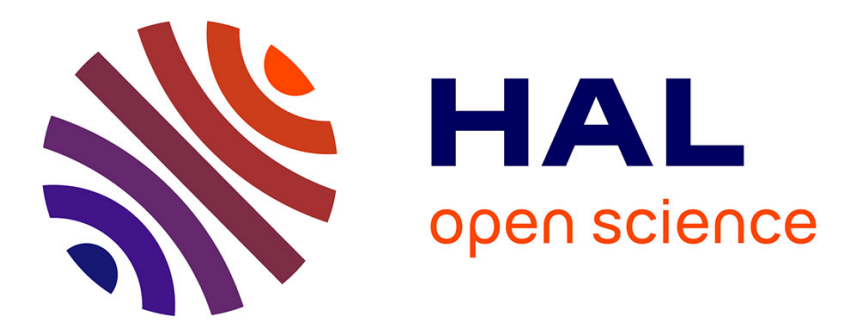

\title{
Relationship between Strength Level and Pedal Rate
}

François Bieuzen, Fabrice Vercruyssen, Christophe Hausswirth, Jeanick

Brisswalter

\section{To cite this version:}

François Bieuzen, Fabrice Vercruyssen, Christophe Hausswirth, Jeanick Brisswalter. Relationship between Strength Level and Pedal Rate. International Journal of Sports Medicine, 2007, 28 (7), pp.585-589. 10.1055/s-2007-964859 . hal-01708157

\section{HAL Id: hal-01708157 \\ https://hal-insep.archives-ouvertes.fr/hal-01708157}

Submitted on 13 Feb 2018

HAL is a multi-disciplinary open access archive for the deposit and dissemination of scientific research documents, whether they are published or not. The documents may come from teaching and research institutions in France or abroad, or from public or private research centers.
L'archive ouverte pluridisciplinaire HAL, est destinée au dépôt et à la diffusion de documents scientifiques de niveau recherche, publiés ou non, émanant des établissements d'enseignement et de recherche français ou étrangers, des laboratoires publics ou privés. 
Article publié dans : International journal of sports medicine ISSN 0172-4622, 2007, 28, (7), 585 589 (DOI 10.1055/s-2007-964859)

\title{
Relationship between Strength Level and Pedal Rate
}

\author{
F. Bieuzen ${ }^{1}$, F. Vercruyssen ${ }^{1}$, C. Hausswirth ${ }^{2}$, J. Brisswalter ${ }^{1}$ \\ 1 Department of Ergonomics, University of Toulon Var, Toulon, France \\ 2 Department of Biomechanics and Physiology, Insep, Paris, France
}

\begin{abstract}
The purpose of this study was to examine the relationship between strength capacity and preferred and optimal cadence in well trained cyclists. Eighteen cyclists participated in this study. Each subject completed three sessions. The initial session was to evaluate the maximal isokinetic voluntary contraction level of lower limb. The second session was an incremental test to exhaustion. During the third session subjects performed a constant cycling exercise (20min) conducted at five randomly cadences $(50,70,90,110 \mathrm{rpm})$ and at the preferred cadence (FCC) at the power reached at ventilatory threshold. Cardiorespiratory and EMG values were recorded. A metabolic optimum (EOC) was observed at $63.5 \pm 7.8 \mathrm{rpm}$ different from preferred cadence (FCC, $90.6 \pm 9.1 \mathrm{rpm}$ ). No difference was found between FCC and the neuromuscular optimal cadence (NOC, $93.5 \pm 4$ ). Significant relationships were found between EOC, NOC and strength capacities $(r=-0.75$ and -0.63$)$, whereas FCC was only related with $V^{\cdot} \mathrm{O} 2 \mathrm{max}(r=0.59)$. The main finding of this study was that during submaximal cycling energetically optimal cadence or neuromuscular optimum in trained cyclists was significantly related with strength capacity and whereas preferred cadence seems to be related with endurance training status of cyclists. Key words : cyclists ; freely chosen cadence ; strength capacity ; energetical optimum ; neuromuscular optimum
\end{abstract}

\section{Introduction}

During road cycling, performance is limited by numerous physiological or biomechanical factors. Among it has been suggested that performance during submaximal cycling is related to the capacity of the subject to sustain maximal locomotion speed with low metabolic energy expenditure during the whole race [1,17]. Within this framework, the more economical athlete should theoretically be able to move faster, or conserve energy for the later stage of an event better, than a less economical athlete. This capacity is assessed by the measurement of the energy cost of locomotion that also reflects the biomechanical demand associated with changes in movement pattern $[1,6,32]$. Therefore, in order to minimize the energy cost of locomotion, the choice of a particular cadence in cycling or running is classically evoked by coaches and researchers [24]. For running or walking, the relation between movement frequencies and energy cost has been widely studied, often suggesting that the performer spontaneously adopts the pattern of locomotion leading to the lowest energy cost [3]. This does not appear to be the case for cycling. On the one hand the energetically optimal cadence ranges from $40 \mathrm{rpm}$ to 80 rpm in trained or untrained cyclists $[2,4,12,19]$ but, observations of cyclists often reveal a 
significant difference between their preferred and most economical cadences [10]. The following functional assumptions have been made to explain this apparent conflict: changes in pedaling forces [26], neuromuscular activation [29], aerobic power or cycling experience [20]. Although these parameters could influence the relationship between energy cost and cadence, the lack of consistence of literature results highlights the difficulty in identifying precisely explain factors of the difference $[1,19,21]$. In fact, optimization principles governing locomotion for cycling are probably as numerous as for other forms of locomotion, and it has been classically described in motor control studies that the adoption of a specific locomotor pattern could be seen as a function of (a) the task constraints and (b) the constraints of the performer [15]. Within this framework, Marsh and Martin [19] hypothesized that preferred cadence could be related to muscular properties of the lower extremity muscles. At each cadence a corresponding mean torque value is associated and therefore a specific force is applied on the pedals. This mean torque or force corresponds to a percentage of the maximum strength capacity that differs between subjects. Indeed, during cycling at the same cadence, the corresponding mean torque will correspond to a lower percentage of maximal force capacity for the stronger cyclists. To the best of our knowledge, no previous study has examined the relation between the choice of a particular cadence and the strength capacity of the cyclists. Therefore, the purpose of this study is to examine the relationship between strength capacity and preferred, most economical and optimal neuromuscular cadences.

\section{Methods}

\section{Subjects}

Eighteen trained and motivated male cyclists (age: $31.6 \pm 5.2$ years; mass: $71.4 \pm 7.0 \mathrm{~kg}$; height: $1.77 \pm 0.06 \mathrm{~m}$ ) who currently took part in competition at national level served as subjects in this study. Each laboratory session was undertaken during the "pre-competition" (i.e. winter: January) period of the sport season. Before participating in this study, subjects were fully informed about the protocol, and informed consent was obtained prior to all testing. This study was approved by a local research ethics committee. Each subject completed three laboratory based testing sessions separated by at least $48 \mathrm{~h}$ rest period.

\section{Experimental procedures}

\section{Maximal isokinetic voluntary contraction}

The initial session was to evaluate the maximal isokinetic voluntary contraction level (MVCi) of lower extremity limb from a squat movement conducted on a specific ergometer (Ariel Dynamics Inc., type Ariel Computerized Exercise System [ACES] "multifunction exercise", Trabuco Canyon, CA, USA) validated by Grooten et al. [11]. Before each session, the ergometer was calibrated according to manufacturer specifications. The range of motion was standardized so that the movement started from zero position with a trunk/thigh angle of 908 and finished with an extended lower limb (knee angle = 1808). All subjects were familiarized with this ergometer and have made a warm-up of two set of ten repetitions at a velocity of $65 \mathrm{~cm} \cdot \mathrm{s}-1$ before the squat evaluation. Each subject performed three sets of two repetitions of maximal isokinetic squat at two different velocities (16 and $8 \mathrm{~cm} \cdot \mathrm{s}-1)$. A short rest time was imposed between each repetition (30 sec) and each set $(5 \mathrm{~min})$. The subjects were instructed to push the bar "as fast as possible", and they were encouraged to perform at their maximal capacity. The maximal peak force values (Fmax) were obtained either for isokinetic velocities of 16 or $8 \mathrm{~cm} \cdot \mathrm{s}-1$. Since body mass (BM) values are different between subjects and thus could affect force capacities, Fmax 
was also expressed according to body mass values (Fmax/BM). For all subjects, the right leg was their dominant leg.

\section{Incremental cycling exercise}

Subjects were then asked to perform an incremental cycling session on an electromagnetically braked ergocycle (Lode, type Excalibur, Gröningen, The Nederland) at the self-selected cadence. The handlebars and racing seat are fully adjustable both vertically and horizontally to reproduce conditions known to subjects from their own bicycles. Moreover, this ergometer was equipped with individual racing pedals and toes clips allowing subject to wear their own cycling shoes. The ergometer allowed subjects to maintain the power output constant independent of the selected cadence, by automatically adjusting torque to angular velocity. The test began with a warm-up of $100 \mathrm{~W}$ lasting $6 \mathrm{~min}$, after which the power output was increased by $30 \mathrm{~W}$ each minute until the subjects were exhausted. The criteria used for the determination of maximal oxygen uptake ( $V^{*} \mathrm{O} 2 \mathrm{max}$ ) were a plateau inVO2max despite an increase in work rate and a respiratory exchange ratio (RER) above 1.1 or a heart rate (i.e. HR) over $90 \%$ of the predicted maximal HR [13]. The four highest consecutive VO2 values were summed in the last stage to determine $\mathrm{V}^{\circ} \mathrm{O} 2 \mathrm{max}$. In addition, the ventilatory threshold (VT) was determined by using the criteria of an increase VE/VO2 with non-concomitant increase of VE/VCO2 [31] (VE, expiratory flow). Visual evaluation to determine VT was carried out independently by three experienced investigators.

\section{Constant cycling exercise}

Before starting the third session, subjects were placed in a seated position and were securely strapped into the test chair to perform an isometric knee extension and flexion using an isometric ergometer (Type: Schnell Trainingsgesäte $\mathrm{GmbH}$, Peutenhausen, Deutschland). The studied limb was the right leg. Subjects sat with a 908 knee angle (08 as full leg extension), with the ankle attached to the ergometer arm. The knee axis was aligned with the dynamometer axis. Surface electromyographic signal (EMG) was recorded on vastus lateralis $(V L)$ during the knee extensors maximal voluntary contraction (MVC, N), and on biceps femoris (BF) during the knee flexors MVC. Subjects performed two maximal isometric contraction of short duration (2-3 s) of the knee flexor and extensor muscles. A $60 \mathrm{~s}$ period of rest was imposed between each contraction. The maximal force values in knee extension and flexion movement were measured using a strength sensor and the best performance consecutive to the two trials was selected as the MVC. Maximal integrated EMG values were calculated for VL and BF muscles during MVC (period of $500 \mathrm{~ms}$ ), and were used to normalize the neuromuscular activity recorded during cycling according to Hunter et al. [14].

Subsequently, subjects performed a constant cycling exercise (20min) conducted at five randomly assigned cadences (4 min at 50, 70, 90, $110 \mathrm{rpm}$ and the preferred cadence [FCC]) for a power output corresponding to the work rate reached at VT $(222.6 \pm 25.9 \mathrm{~W})$. A bicycle computer with a cadence monitor provided feedback to subjects so that the cadence could be maintained within $\pm 1 \mathrm{rpm}$ of the target cadence during the duration of test. For the FCC trial, the cadence monitor was covered and the subject was asked to cycle at a cadence considered as the most comfortable during an extended period of time $(>1 \mathrm{~h})$. The cadence was continuously monitored during the overall cycling exercise. Moreover, pulmonary gas exchanges were measured using a portable telemetric gas exchange system (Cosmed K4RQ $®$, Rome, Italia) and the EMG activity was recorded on the right VL and BF muscles during the overall cycling bout. The Cosmed K4RQ $®$ was calibrated prior to each experimental session according to external temperature and humidity. Cardiorespiratory and EMG data were recorded during the fourth minute at each imposed cadence (50, 70, 90 and $110 \mathrm{rpm})$ and at FCC. It was assumed that a steady state was achieved when four consecutive $30 \mathrm{~s} \mathrm{~V}^{\cdot} \mathrm{O} 2$ readings were within \pm 1 
$\mathrm{ml} \cdot \min -1 \cdot \mathrm{kg}-1$ of each other. All subjects were able to reach this criterion after $2-3 \mathrm{~min}$ of cycling.

\section{Measurement of EMG signal}

The muscles activities of VL and BF muscles of the right leg, selected for their high contribution to the propulsive cycling task [28], were monitored with surface EMG. The subjects were prepared for placement of EMG electrodes by shaving the skin of each electrode site, cleaning it carefully with alcohol swab and lightly abrading it to maintain a low inter-electrode resistance of $<1000$ W. Pairs of Ag/AgCl pre-gelled surface electrodes (Medicotest, type Blue Sensor, Q-00$\mathrm{S}$, Copenhagen, Denmark) of $40 \mathrm{~mm}$ diameter with a center to center distance of $25 \mathrm{~mm}$ were applied along the fibers over the bellies of the two muscles for EMG data acquisition. The electrodes were secured with chirurgical tape and cloth wrap to minimize disruption during the movement. A ground electrode was placed on a bony site over the right anterior superior spine of the iliac crest.

EMG signals were pre-amplified closed to detection site (Common Mode Rejection Ratio, CMRR $=100 \mathrm{~dB} ; \mathrm{Z}$ input $=10 \mathrm{G} \phi \mathrm{W} ;$ gain $=600$, bandwidth frequency $=$ from $6 \mathrm{~Hz}$ to $1600 \mathrm{~Hz}$ ). Prior to acquisition, a third order, zero lag Butterworth antialiasing filter at $500 \mathrm{~Hz}$ was applied. EMG data were collected from each muscle during 40 consecutive crank cycles during the last minutes of each cadence. Data were digitized through an acquisition board (DT 9800-series, Data Translation, Marlboro, VT, USA) and stored on a computer to be analyzed using custom-written addon software (Origin 6.1®, OriginLab, Northampton, MA, USA). The EMG data were sampled at $1000 \mathrm{~Hz}$, normalized (normalized EMG) to muscle maximal EMG obtained during MVC test for each individual muscle and analyzed on all 40 consecutive crank cycles.

\section{Statistical analyses}

All data were expressed as mean \pm standard deviation (SD). Based on previous studies, the relationships between $\mathrm{VO} 2$ and pedaling cadence [2,4,19-21] but also between the sum of normalized VL and BF integrated electromyogram signal (iEMG) and pedaling cadence [22,23] for each subject were fitted using a polynomial regression with a quadratic model. The minimum point of the U-shape represented the theoretical energetically optimal cadence (EOC) and the theoretical neuromuscular optimal cadence (NOC). Relationship between dependant variables and differences between cycling cadence optima were analyzed using both Parametric and non Parametric correlation tests. The 0.05 level of significance was used for all statistical procedures.

\section{Results}

Table 1 shows the mean values in MVCi, VO2max, the maximal aerobic power (Pmax) and the power output at VT concerning the experimental group.

A quadratic relationship was observed between VO2 and cadence with the identification of the EOC at $63.5 \pm 7.8 \mathrm{rpm}$ significantly different from FCC $(90.6 \pm 9.1 \mathrm{rpm})$. No significant difference was found between FCC and NOC (93.5 $\pm 4.0 \mathrm{rpm}$ ) (Fig. 1). Relationships between dependant variables are presented Table 2. Significant negative relationships were found between EOC and strength capacities (respectively for Fmax, Fmax/BM and the maximal velocity (Vmax), $r=-$ $0.75 ;-0.67$ and -0.73 ). Furthermore, a significant relationship was found between NOC, EOC and Fmax (respectively $r=0.69$ and -0.63 ), whereas FCC was only significantly related with VO2max and BM (respectively $r=0.59$ and 0.56 ).

A previously evocated, a significant relationship was found between resultant force applied on the pedal and Fmax but only for $50 \mathrm{rpm}$ (respectively for 50, 70, 90, $110 \mathrm{rpm}, r=0.46[S$ ], $0.28[\mathrm{NS}], 0.11[\mathrm{NS}], 0.08[\mathrm{NS}])$. 
Table 1 Characteristics of subjects

\begin{tabular}{|l|l|l|l|l|l|l|l|}
\hline $\begin{array}{l}\text { Subjects } \\
(\mathbf{N}=18)\end{array}$ & $\begin{array}{l}\text { VO2max } \\
(\mathbf{m l} \\
\bullet \mathbf{m i n}-1 \\
\mathbf{k g}-1)\end{array}$ & $\begin{array}{l}\text { Pmax } \\
\mathbf{( W )}\end{array}$ & $\begin{array}{l}\text { VT } \\
\mathbf{( W )}\end{array}$ & $\begin{array}{l}\text { Vmax } \\
(\mathbf{m} \cdot \mathbf{s}-\mathbf{1})\end{array}$ & $\begin{array}{l}\text { Fmax } \\
(\mathbf{N})\end{array}$ & $\begin{array}{l}\text { Fmax/BM } \\
(\mathbf{N} \cdot k g-1)\end{array}$ & $\begin{array}{l}\text { BM } \\
(\mathbf{k g})\end{array}$ \\
\hline Mean & 65.3 & 402.8 & 222.6 & 0.264 & 1717.1 & 19.0 & 73.0 \\
\hline SD & 7.1 & 32.2 & 25.9 & 0.027 & 284.6 & 3.1 & 6.7 \\
\hline
\end{tabular}

VO2max: maximal oxygen uptake; Pmax: maximal aerobic power; VT: ventilatory threshold; Vmax: maximal velocity; Fmax: maximal peak force; BM: body mass

Table 2 Relationship between strength capacity, physiological optima and preferred cadence

\begin{tabular}{|c|c|c|c|c|c|c|c|c|c|}
\hline & $\begin{array}{l}\text { EOC } \\
\text { (rpm) }\end{array}$ & $\begin{array}{l}\text { V02max } \\
\text { (ml } \\
\cdot \text { min-1 } \\
\cdot k g-1)\end{array}$ & $\begin{array}{l}\text { Pmax } \\
\text { (W) }\end{array}$ & $\begin{array}{l}\text { VT } \\
\text { (W) }\end{array}$ & $\begin{array}{l}\text { Vmax } \\
(\mathrm{m} \cdot \mathrm{s}- \\
1)\end{array}$ & $\begin{array}{l}\text { NOC } \\
\text { (rpm) }\end{array}$ & $\begin{array}{l}\text { Fmax } \\
(\mathrm{N})\end{array}$ & $\begin{array}{l}\text { Fmax/BM } \\
(\mathrm{N} \cdot k g-1)\end{array}$ & $\begin{array}{l}\text { FCC } \\
\text { (rpm) }\end{array}$ \\
\hline \multicolumn{10}{|l|}{ EOC } \\
\hline VO2max & 0.02 & & & & & & & & \\
\hline Pmax & -0.44 & 0.40 & & & & & & & \\
\hline VT & -0.47 & $0.55^{*}$ & $0.51^{*}$ & & & & & & \\
\hline Vmax & $-0.73^{*}$ & 0.19 & 0.46 & 0.22 & & & & & \\
\hline NOC & $0.69^{*}$ & 0.10 & -0.35 & -0.28 & -0.46 & & & & \\
\hline Fmax & $-0.75^{*}$ & -0.05 & $0.50^{*}$ & 0.16 & $0.83^{*}$ & $-0.63^{*}$ & & & \\
\hline Fmax/BM & $-0.67^{*}$ & 0.31 & 0.35 & 0.26 & $0.88^{*}$ & -0.46 & $0.84^{*}$ & & \\
\hline FCC & -0.16 & $0.54^{*}$ & 0.15 & -0.23 & 0.28 & -0.15 & 0.37 & 0.03 & \\
\hline BM & -0.25 & $-0.59^{*}$ & 0.29 & -0.15 & 0.05 & -0.40 & 0.44 & -0.11 & $0.56^{*}$ \\
\hline
\end{tabular}

EOC: energetically optimal cadence; $\mathrm{V}^{\circ} \mathrm{O} 2 \mathrm{max}$ : maximal oxygen uptake; Pmax: maximal aerobic power; VT: ventilatory threshold; Vmax: maximal velocity; NOC: neuromuscular optimal cadence; Fmax: maximal peak force; BM: body mass; FCC: preferred cadence. * when a statistical relationship was found between dependant variables, $p<0.05$

\section{Discussion}

Based on the hypothesis of Marsh and Martin [19], the objective of the current study was to examine the relationship between strength capacity and cadences corresponding to physiological optima or FCC. The main finding of this study was that energetically optimal cadence (EOC) at submaximal power in trained cyclists was significantly related with strength capacity and NOC whereas FCC was only correlated with Pmax.

According to previous literature, our cyclists have naturally selected a cadence (range: 77-114 rpm) significantly higher than the EOC (range: 51-73 rpm) but not significantly different from NOC (range: 84-99 rpm) (I" Fig. 1). Furthermore, no significant relationship was found between 
either EOC or NOC and FCC. These results support, on the one hand, the fact that minimization of aerobic demand is not a critical determinant of self-selected cadence during a cycling exercise of $\sim 200 \mathrm{~W}$ in trained subjects $[2,19,21,29,30]$. In fact, during cycling a systematic difference is observed between EOC (50-60 rpm) and the self-selected cadence (80-90 rpm) reported either in trained cyclists and runners [19] or highly trained triathletes [30]. However, it seems that training and practicing level of the subjects affect the EOC. Indeed, the EOC ( $80 \mathrm{rpm})$ of experimented [7, 8] and professional road cyclists [18] was higher than the EOC found on Marsh and Martin's subjects [19]. On the other hand, complementary studies have tried to analyze the FCC using criteria other than the minimization of energy expenditure, such as an optimization of the force applied to the cranks, a minimization of the lower extremity net joint moments [21, 23] or iEMG of the muscles [29]. In our study neuromuscular optimal values (93.5 $\pm 4.0 \mathrm{rpm}$ ) could be compared with previous results of the literature. For example, Takaishi et al. [29] noted a quadratic relationship with a reduced EMG activity (VL) at 80 and $90 \mathrm{rpm}$. However in our study no significant relationship was observed between NOC and FCC ( $r=-0.15, N S)$. This result could be linked for one part to the difficulty raised in the literature to obtain consistent results on NOC determination. In this context, Neptune et al. [22] showed that gluteus maximus and soleus muscles had significant quadratic trends with minimum values at $90 \mathrm{rpm}$ whereas hamstring and vastus medialis muscles systematically increased muscle activity as pedaling cadence increased. Furthermore, Marsh andMartin [15] indicated a reduced EMG activity (VL, rectus femoris, soleus and gastrocnemius) at cadences ranging from 50 to $65 \mathrm{rpm}$ for a power output of $200 \mathrm{~W}$. These contradictory results obtained on various muscles and across different cadences make difficult the explanation of the FCC exclusively from the iEMG-based measures in trained cyclists. In this study the only significant relationship was found between FCC and V' O2max values $(r=0.54)$. This result could be compared with previous results by Marsh and Martin [21] indicating that trained cyclists and runners of equal aerobic fitness level spontaneously adopt a similar cadence during cycling exercises conducted at a power output of $200 \mathrm{~W}$. These authors concluded that the reduction of aerobic demand and cycling experience are not key determinants of self-selected cadence in trained subjects but could be linked to endurance training status. Force velocity $(\mathrm{F}-\mathrm{V})$ properties of the lower extremity were often suggested to explain the choice of a particular cadence [16,19] muscles. Also, Marsh andMartin [19] hypothesized that the similar preferred cadences of trained cyclists and runners compared to less trained subjects are due to similarities in the F-V properties of the lower extremity muscles developed during endurance training (i.e. high repetitions or relatively fast joint angular velocities). Therefore, changes in the mechanical properties of muscle induced by the training characteristics may coincide with changes in FCC. Our results do not directly validate the hypothesis by Marsh and Martin [19] since no significant relationship was found between strength capacities and FCC. It must be noted that, in this investigation, the use of an isokinetic dynamometer did allow to assess only indirectly the F-V properties in vivo from a set of squat movements since the direct comparison with the F-V curves obtained in vitro has not been clearly established [25]. Therefore further studies conducted at different power outputs are necessary in attempt to validate the hypothesis regarding the influence of muscular properties on the self-selected cadence.

On the opposite, one interesting result of this study is the significant negative relationship between EOC and strength capacities (Fig. 2). During moderate exercise, several factors could explain the change in energy cost with increasing cadence. On the one hand, the rise in the ventilation cost and/or the increase in internal work for repetitive limb movements have been classically hypothesized to explain the increase in energy cost [5,9]. Francescato et al. [9] indicated that the fraction of overall VO2 due to internal work for a subject cycling at $100 \mathrm{~W}$ and $60 \mathrm{rpm}$ was about 0.2 whereas this fraction was around 0.6 at $100 \mathrm{rpm}$. In addition, Coast et al. [5] indicated that the cost of ventilation estimated from the increase in the work of breathing (i.e. variations in VE) could explain at least $30 \%$ of theVO2 rise. Therefore for moderate cadence we 
could expect a rise in energy cost of locomotion with the increase in cadence. On the other hand, one of the factors often used to explain changes in energy cost of locomotion and pedal cadence manipulation is modification in muscle fiber recruitment [2,27]. Within this framework, Woledge [33] has suggested that the shift from type I to type II fibers (which have a lower muscle efficiency than type I fibers) could be linked to a decrease in thermodynamic muscle efficiency leading to an increase in energy cost. Thus, in our study one hypothesis could relate the relationship between strength capacities and EOC with muscle fibers recruitment. It is well established that a reduction in forces application on the cranks, minimum values of the average individual muscle activation, occur at a cadence of $90 \mathrm{rpm}$ during a submaximal steady-state cycling [23]. Therefore in stronger cyclists force applied on the pedals at low cadence corresponds to a lower percentage of the maximum strength capacity allowing them to recruit more type I fiber more economically; on the opposite, weaker cyclists need to increase pedal rate to decrease the force applied on the pedals. Thus in stronger cyclists at submaximal intensities we can hypothesize that an increase in energy cost with pedal cadence is mainly related to the increase in internal work or ventilation whereas in weaker cyclists the relationship between cadence and energy cost results from both optimal force applied on the pedals and internal or ventilation work. This result gives indirect evidence to the fact that the relationship between cadence and energy cost is specific to the task constraints and the constraints of the performer. Further studies using different cycling intensities are necessary to validate this hypothesis

Fig. 1 Physiological optima and preferred cadence in the experimental population.

EOC: energetically optimal cadence; NOC: neuromuscular optimal cadence; FCC: preferred cadence; VO2: oxygen uptake; iEMG: integrated EMG.

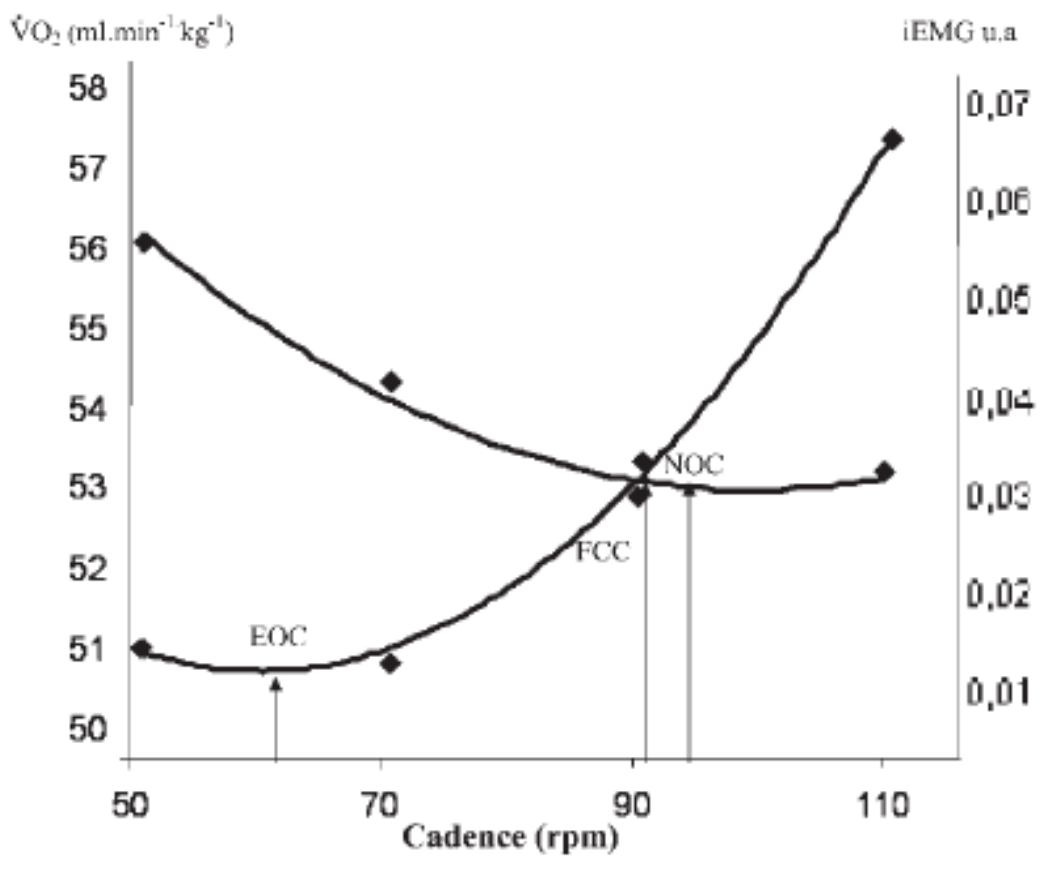


Fig. 2 Relationship between energetically optimal cadence and Fmax Fmax: maximal peak force; EOC: energetically optimal cadence.

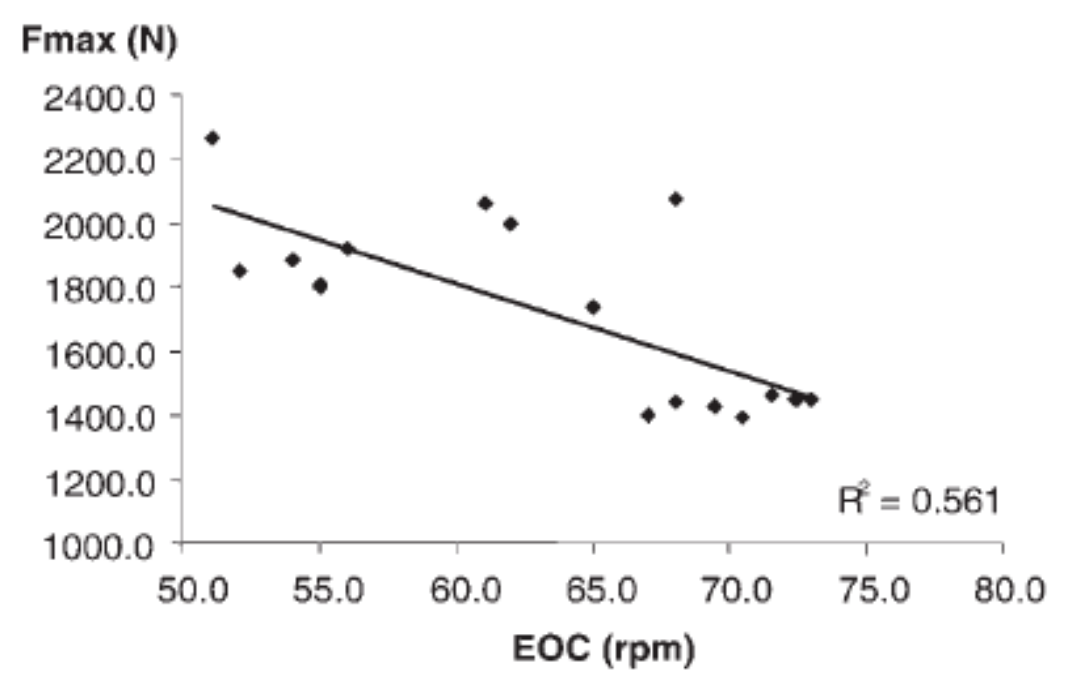

\section{References}

1 Abiss CR, Laursen PB. Models to explain fatigue during prolonged endurance cycling. Sports Med 2005; 35: 1-32

2 Brisswalter J, Hausswirth C, Smith D, Vercruyssen F, Vallier JM. Energetically optimal cadence vs. freely-chosen cadence during cycling: effect of exercise duration. Int J Sports Med 2000; 21: 60-64

3 Brisswalter J, Mottet D. Energy cost and stride duration at preferred transition gait speed between walking and running Can J Appl Physiol 1996; 21: 471-480

4 Coast JR, Cox RH, Welch HG. Optimal pedalling rate in prolonged bouts of cycle ergometry. Med Sci Sports Exerc 1986; 18: 225-230

5 Coast JR, Rasmussen SA, Krause KM, O'Kroy JA, Loy RA, Rhodes J. Ventilatory work and oxygen consumption during exercise and hyperventilation. J Appl Physiol 1993; 74: 793798

6 Di Prampero PE. The energy cost of human locomotion on land and in water. Int J Sports Med 1986; 7: 55-72

7 Foss $\mathrm{O}$, Hallen J. The most economical cadence increases with increasing workload. Eur J Appl Physiol 2004; 92: 443-451

8 Foss O, Hallen J. Cadence and performance in elite cyclists. Eur J Appl Physiol 2005; 93: 453-462

9 Francescato MP, Girardis M, di Prampero PE. Oxygen cost of internal work during cycling. Eur J Appl Physiol 1995; 72: 51-57

10 Gregor RJ, Broker JP, Ryan MM. The biomechanics of cycling. Exerc Sport Sci Rev 1991; 19: 127-168

11 Grooten WJ, Puttermans V, Larsson RJ. Reliability if isokinetic supine bench press in healthy women using the Ariel Computerized Exercise System. Scand J Med Sci Sport 2002; 12: 218-222 
12 Hansen EA, Andersen JL, Nielsen JS, Sjogaard G. Muscle fiber type, efficiency, and mechanical optima affect freely chosen pedal rate during cycling. Acta Physiol Scand 2002; 176: 185-194

13 Howley ET, Basset DR Jr,Welch EG. Criteria for maximal oxygen uptake: review and commentary. Med Sci Sports Exerc 1995; 27: 1292-1301

14 Hunter AM, St Clair Gibson A, Lambert M, Noakes TD. Electromyographic (EMG) normalization method for cycle fatigue protocols. Med Sci Sports Exerc 2002; 34: 857861.

15 Kelso JAS, Scholtz JP, Schöner G. Dynamics governs switching among pattern of coordination in biological movement. Phys Lett A 1988; 134: 8-12

16 Kohler G, Boutellier U. The generalized force-velocity relationship explains why the preferred pedaling rate of cyclists exceeds the most efficient one. Eur J Appl Physiol 2005; 94: 188-195

17 Lucia A, Hoyos J, Chicharro JL. Physiology of professional road cycling. Sports Med 2001; 31: $325-337$

18 Lucia A, San Juan AF, Montilla M, Canete S, Santalla A, Earnet C, Perez M. In professional road cyclists, low pedaling cadences are less efficient. Med Sci Sports Exerc 2004; 36 : 1048-1054

19 Marsh AP, Martin PE. Effect of cycling experience, aerobic power, and power output on preferred and most economical cycling cadences. Med Sci Sports Exerc 1997; 29: 12251232

20 Marsh AP, Martin PE. The association between cycling experience and preferred and most economical cadences. Med Sci Sports Exerc 1993; 25: 1269-1274

21 Marsh AP, Martin PE, Foley KO. Effect of cadence, cycling experience, and aerobic power on delta efficiency during cycling. Med Sci Sports Exerc 2000; 32: 1630-1634

22 Neptune RR, Kautz SA, HullML. The effect of pedalling rate on coordination in cycling. J Biomech 1997; 30: 1051-1058

23 Neptune RR, Hull ML. A theoretical analysis of preferred pedaling rate selection in endurance cycling. J Biomech 1999; 32: 409-415

24 Nesi X, Bosquet L, Pelayo P. Preferred pedal rate :an index of cycling performance. Int J Sports Med 2004; 25: 46-49

25 Osterning LR. Isokinetic dynametry: implications for muscle testing and rehabilitation. Exerc Sport Sci Rev 1986; 14: 45-80

26 Patterson RP, Moreno MI. Bicycle pedalling forces as a function of pedalling rate and power output. Med Sci Sports Exerc 1990; 22: 512-516

27 Poole, DC, Richardson, RS. Determinants of oxygen uptake. Sports Med 1997; 24: 308-320

28 Ryan MM, Gregor RJ. EMG Profiles of lower Extremity Muscles During Cycling at Constant Workload and Cadence. J Electromyogr Kinesiol 1992; 2: 69-80

29 Takaishi T, Yasuda Y, Ono T, Moritani T. Optimal pedalling rate estimated from neuromuscular fatigue for cyclists. Med Sci Sports Exerc 1996; 28: 1492-1497

30 Vercruyssen F, Brisswalter J, Hausswirth C, Bernard T, Bernard O, Vallier JM. Influence of cycling cadence on subsequent running performance in triathletes. Med Sci Sports Exerc 2002; 34: 530-536

31 Wasserman K, Whipp BJ, Koyl SN, Beaver WL. Anaerobic threshold and respiratory gas exchange during exercise. J Appl Physiol 1973; 35: 236-243

32 Williams KR. The relationship between mechanical and physiological energy estimates. Med Sci Sports Exerc 1985; 17: 317-325

33 Woledge RC. Possible effects of fatigue on muscle efficiency. Acta Physiol Scand 1998; 162 : 267-273 